\title{
REGULARIZAÇÃO FUNDIÁRIA PARA PRESERVAÇÃO AMBIENTAL: NOVA ESPERANÇA
}

\author{
REGULARIZACIÓN DE LA TIERRA PARA LA PRESERVACIÓN DEL MEDIO AMBIENTE: NOVA \\ ESPERANÇA
}

LAND REGULARIZATION FOR ENVIRONMENTAL PRESERVATION: NOVA ESPERANÇA

\section{BORGES, IGOR ALVES}

Urbanista. Mestrando em Planejamento e Gestão do Território UFABC. Especialista em Assistência Técnica em Habitação e Direito a Cidade, UFBA. E-mail: i.borges@ufabc.edu.br

\section{GORDILHO-SOUZA, ANGELA MARIA}

Arquiteta, Doutora em Arquitetura e Urbanismo USP, Profa. do PPGAU-FAUFBA. E-mail: amgs@ufba.br

\section{A COMUNIDADE DE CEPEL EM NOVA ESPERANÇA}

O bairro de Nova Esperança está inserido na Área de Preservação Ambiental - APA - Joanes Ipitanga na Região Metropolitana de Salvador (RMS). Esta área possui uma rica biodiversidade, contendo. em seu território, os mananciais Ipitanga I, II e III, os quais são responsáveis pelo abastecimento de água de $40 \%$ da população da RMS. Essas condições propiciaram a institucionalização de um Parque Metropolitano (BAHIA, 1986). Em seu zoneamento, definido pelo Conselho Estadual de Meio Ambiente (BAHIA, 1999), são impostas restrições de uso e ocupação do solo na área da APA; no entanto, para atender às pressões imobiliárias, comerciais e industriais, as restrições têm sido cada vez mais flexibilizadas.

Figura 1: Localização de Nova Esperança na Região Metropolitana de Salvador

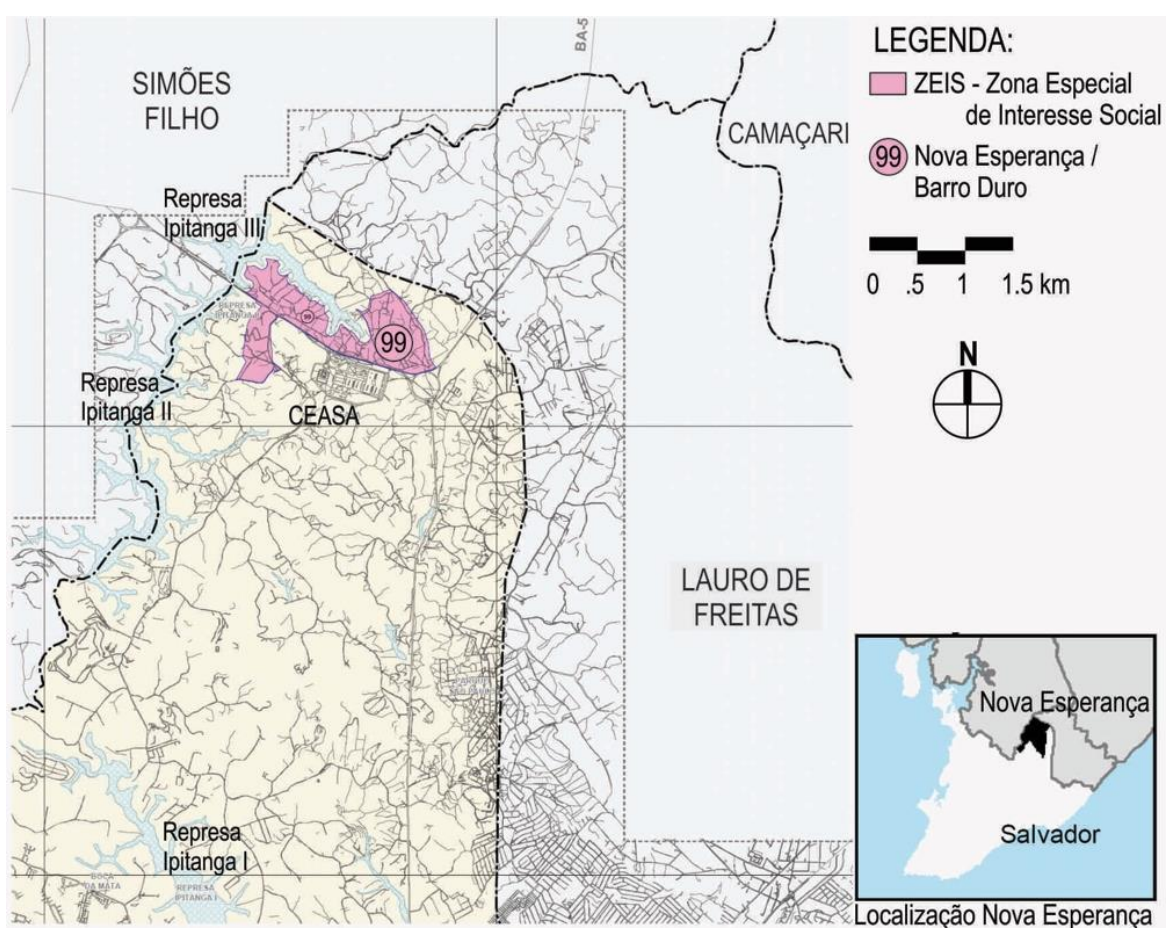

Fonte: Plano Diretor de Desenvolvimento Urbano de Salvador (2012) 
Ao longo das últimas décadas, diversos tipos de ocupação se desenvolveram na área, de forma inapropriada para uma área de tamanho interesse ambiental: aterro sanitário, usos industriais, agropecuária, além de diversos assentamentos precários. Os assentamentos na região apresentam os piores indicadores de saneamento da cidade de Salvador, sem esgotamento sanitário e, paradoxalmente, nem mesmo abastecimento de água em diversos locais. A ocupação habitacional identificada como CEPEL, área enfocada por este projeto, constitui um dos assentamentos precários em Nova Esperança.

A localidade de CEPEL fica às margens do manancial Ipitanga III (Figura 1), sendo esta a represa mais poluída do sistema de abastecimento Ipitanga, a qual recebe lançamentos de esgotos e disposição de resíduos sólidos gerados no seu entorno. A comunidade de CEPEL, em 2010, segundo o Censo (IBGE, 2010), constituía uma população de 1.654 habitantes, em 530 domicílios, distribuídas numa área de 50 ha, o que representa uma densidade de $33 \mathrm{hab} / \mathrm{ha}$., ainda baixa, se comparada à de outros bairros autoconstruídos da cidade. Traz em seu histórico de ocupação um processo de apropriação do solo, com muita luta, o que torna a sua permanência bastante relevante. A equipe que desenvolveu os trabalhos da Residência AU+E/UFBA nessa área entendeu que esta comunidade poderia ser a maior parceira para a preservação do meio ambiente e manutenção da qualidade dos recursos hídricos deste manancial, pressuposto que embasou o projeto a seguir apresentado. ${ }^{1}$

\section{A AÇÃO DA ASSISTÊNCIA TÉCNICA}

Este projeto de assistência técnica dialoga com o projeto de urbanização elaborado pela Companhia de Desenvolvimento Urbano da Bahia (CONDER), em 2009, com recursos do Programa de Aceleração do Crescimento (PAC), que, com o objetivo de gerar o mínimo de remoções possíveis, estabeleceu que o limite da Área de Proteção Permanente (APP), na margem do manancial, sendo flexibilizada de 100 para 50 metros, conforme se observa na Figura 2, de acordo com determinação do Conselho Gestor da APA. No entanto, esta proposta de delimitação de APP no manancial não tem garantido a sua plena proteção, como pode ser observado neste trabalho, com a disposição de lixo e esgotos nessa faixa, além do início de novas ocupações. Este modelo de proteção na prática demonstra ser ineficaz, pois cria um isolamento entre a população e o meio ambiente, fazendo desta "pintura no mapa" o limite invisível de uma tensão permanente. Em um prognóstico breve, as novas ocupações (re)surgem, visto que se trata de um terreno "sem dono" e sem uso.

Observou-se também que na ocupação de Nova Esperança, ainda que a pressão de uso e ocupação do solo seja permanente, ainda existem significativas parcelas de vegetação preservada às margens da represa. Também existem nos "grotões", indicados na Figura 3, intensa arborização, correspondendo às áreas no fundo das moradias, que mantém usos rurais e onde estão os talvegues de escoamento das águas pluviais. Outra área de extrema importância para esta proposta, foi identificada no miolo do bairro, para a qual a população, por autogestão, destinou uso exclusivamente comunitário, onde existem um campo de futebol, igreja, quadras poliesportivas, escola, posto de saúde e sede da associação de moradores.

A preservação dos recursos hídricos foi um dos elementos de maior destaque apontado pelo trabalho de assistência técnica realizado nesta área, com relevância local e metropolitana. O projeto em tela, voltado para a regularização fundiária em área considerada Zona Especial de Interesse Social (ZEIS), juntamente com outras demandas por assistência técnica em arquitetura e urbanismo, foram extraídos de oficinas realizadas na elaboração de um diagnóstico participativo, visitas de campo e análise de dados primários e secundários.

O desafio colocado para este projeto, em particular, foi como garantir a qualidade e a disponibilidade dos recursos hídricos, combinado à manutenção da ocupação existente com delimitações e usos compatíveis.

O elemento complicador de viabilidade do projeto deve-se à condição de ocupação da área, precária em termos de infraestrutura e de saneamento, sem titulação de propriedade e pressionada pelo mercado formal e informal, por novas ocupações, sem controle efetivo da gestão pública dessa ocupação.

A estratégia encontrada para atender ao desafio de viabilizar ocupação e preservação nesta área foi a de promover a regularização fundiária, de forma sustentável. Através de instrumentos de regularização fundiária e zoneamento, o projeto propõe que, para os terrenos ocupados, seja considerada a delimitação de uma parcela para edificação e de outra parcela para usos agroecológicos. Dessa forma, visualiza-se a regularização fundiária das ocupações existentes de preservação ambiental, ao mesmo tempo em que se formaliza a posse das áreas de uso agroecológico para cada morador, protegendo a área dos mananciais. A proposta não exclui a necessária fiscalização da gestão pública, para que as parcelas agroecológicas sejam respeitadas e, para isso, foi proposta uma ferramenta de governança comunitária. 
Figura 2: Usos e ocupação Nova Esperança

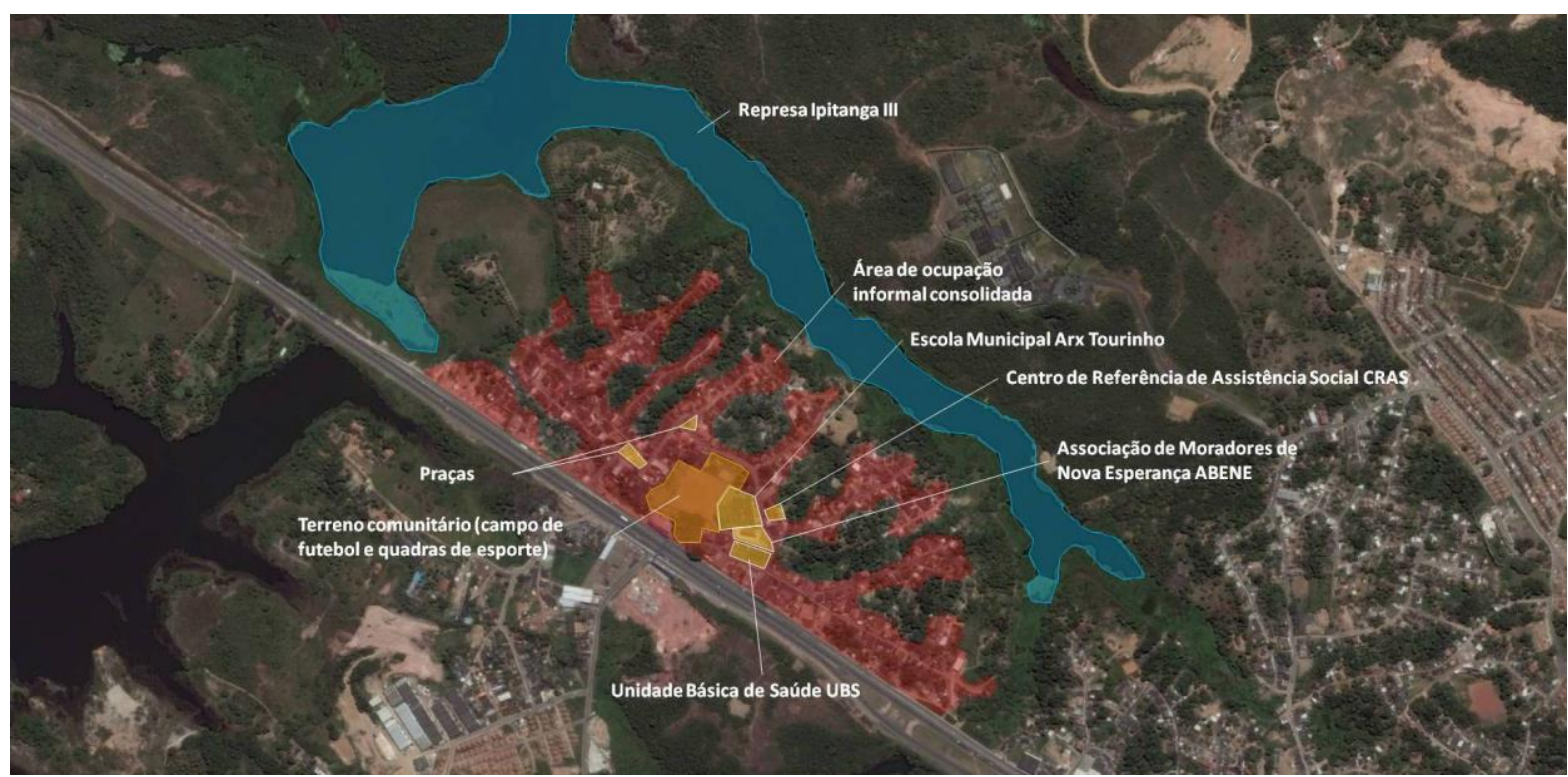

Fonte: Elaboração do autor, com base em aerofotos, 2006-PMS (BORGES, 2015).

Figura 3: Limites da área de proteção permanente e tendência de escoamento das águas pluviais e esgotos

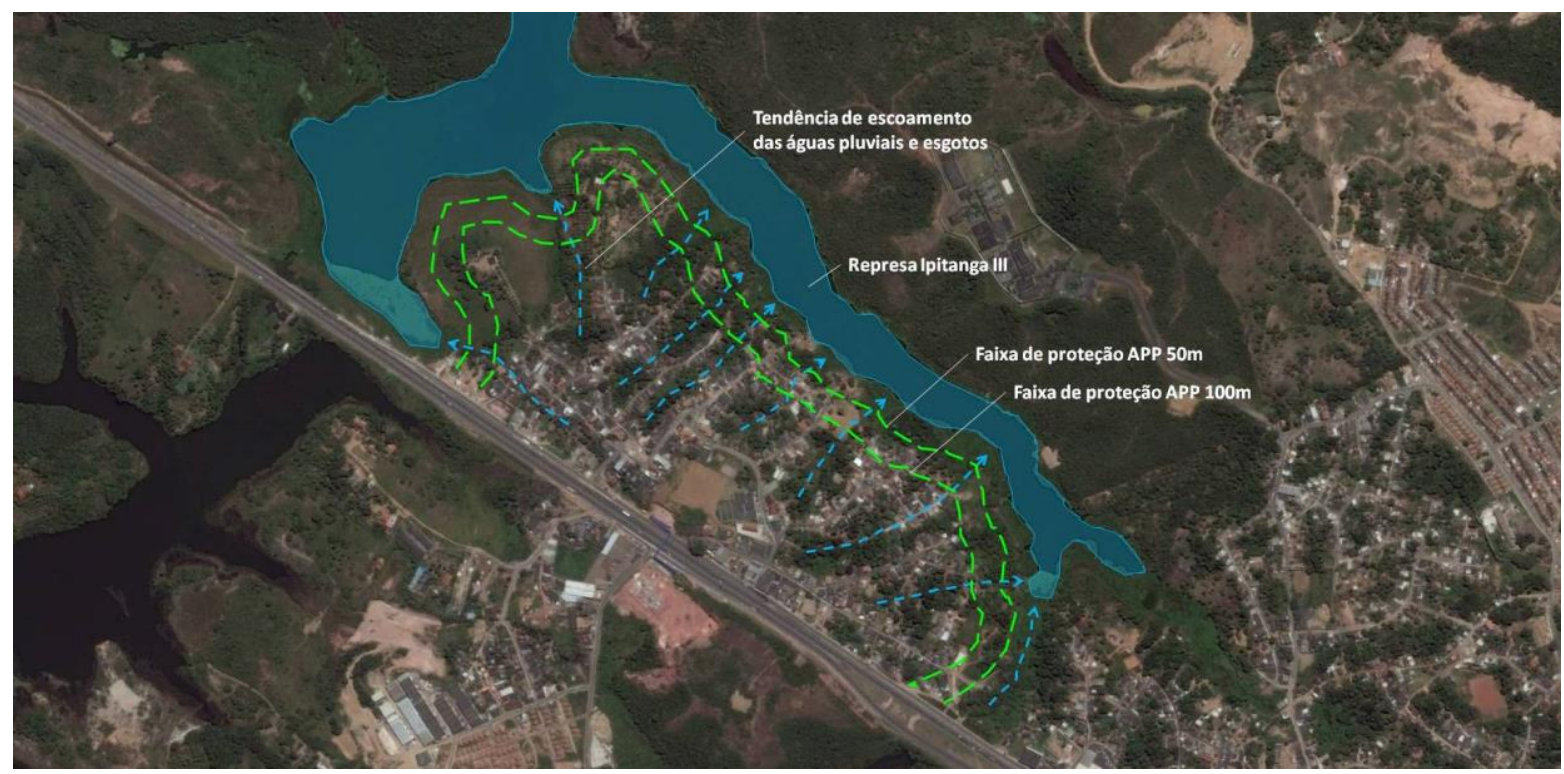

Fonte: Elaboração do autor, com base em aerofotos, 2006-PMS (BORGES, 2015).

As diretrizes para este projeto consideraram a necessidade de manutenção da baixa densidade de ocupação; restrição a novos parcelamentos; preservação da vegetação existente, valorizando a biodiversidade; melhoria das condições de saneamento básico na área; estratégias de enfraquecimento da pressão por mercados informais de terra; fortalecimento da gestão comunitária e da consciência de preservação ambiental.

Este projeto teve como objetivos principais: a) restringir a ocupação de terras do mercado informal, sob pressão na área, por meio do instrumento da regularização fundiária; b) evitar novas ocupações e densificação da área, o que pode comprometer a infraestrutura de saneamento e os recursos naturais; c) reduzir o risco de ocupação privada do terreno comunitário, atribuindo sua posse à comunidade, para fins de equipamentos comunitários, preservação, paisagismo e recreação; d) fortalecer a capacidade de governança da comunidade no compromisso de autogestão do controle do uso e ocupação do solo, garantindo a preservação ambiental e recursos hídricos, em conjugação à gestão pública institucional. 
Figura 4: Áreas não ocupadas, potenciais de preservação Nova Esperança

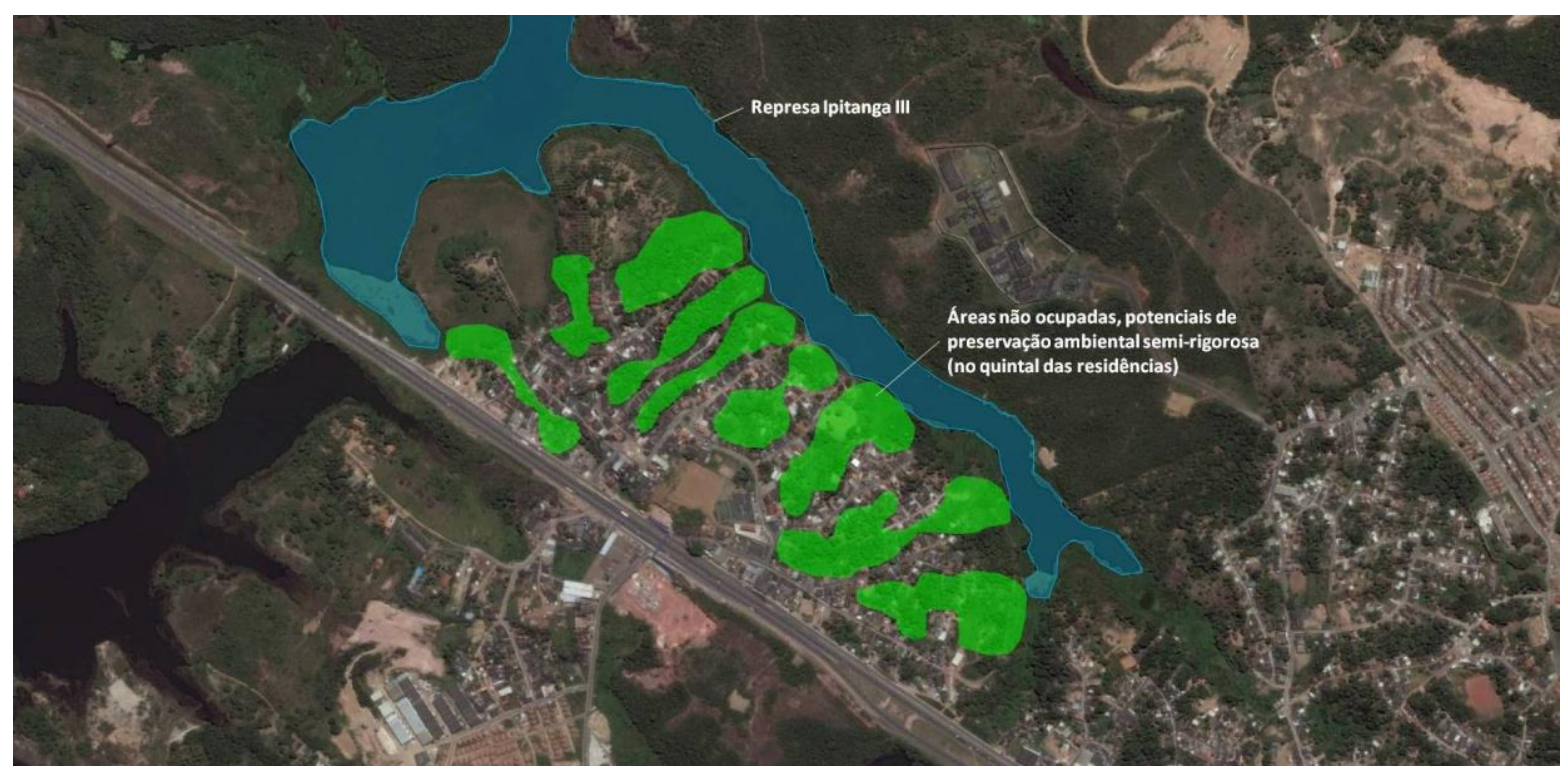

Fonte: Elaboração do autor, com base em aerofotos, 2006-PMS (BORGES, 2015)

A formulação da proposta passa portanto pelo entendimento dos processos intensivos de formação de assentamentos precários nas cidades brasileiras, salientando-se que essa é uma das consequências da propriedade concentrada de terras, da má distribuição de renda e da ausência de políticas públicas de habitação de interesse social, aspectos que tiveram papel fundamental na indução da periferização e segregação nas cidades brasileiras, Para Gordilho-Souza (2006, p. 351), em Salvador, desde a década de 1940, "normas seletivas por tipo de habitação em determinadas áreas urbanas contribuíram para intensificar o processo de segregação espacial da população pobre, empurrada para a periferia desde então".

Nova Esperança não foge a essa regra e, pelas suas características, assume uma posição estratégica exemplar no planejamento da região metropolitana, pois está na franja do município de Salvador, fazendo limite com outros municípios (Lauro de Freitas e Simões Filho), atuando como última fronteira do município capital da RMS (SARNO, 2011). Nesta área, existe uma forte dinâmica por ocupação, formal e informal, por conta do baixo valor da terra.

"O crescimento rápido e desordenado das franjas metropolitanas, a partir de processos de parcelamento do solo realizados por pequenos e médios agentes imobiliários, através dos loteamentos irregulares, bem como pelas ocupações coletivas, recebe incremento dos empreendimentos públicos construídos na periferia para famílias retiradas das áreas centrais, através de programas de remoção e renovação urbana. A crescente especulação imobiliária também contribui para que as famílias de renda mais baixa comercializem seus imóveis situados em áreas mais valorizadas, transferindo-se para periferia" (GORDILHO-SOUZA, 2007, p. 5)

O conceito deste projeto fundamenta-se na ideia de que mercados informais são incapazes de macro organizar o espaço para os interesses coletivos e da sustentabilidade ambiental, sujeitando-o a uma ocupação, intensiva e inadequada, na produção dos assentamentos precários. Considerando que a terra é uma mercadoria no contexto brasileiro e observando a latente pressão por comercialização de vazios de propriedade pública na localidade de CEPEL, faz-se necessária a regularização fundiária e de uso dessa área, evitando que se ampliem os prejuízos ambientais que podem ser causados pelo aumento intensivo de ocupações informais, ao tempo em que se buscam melhores condições de habitabilidade nesta localidade. 
Figura 5 - Proposta urbanística de usos e ocupação para Nova Esperança

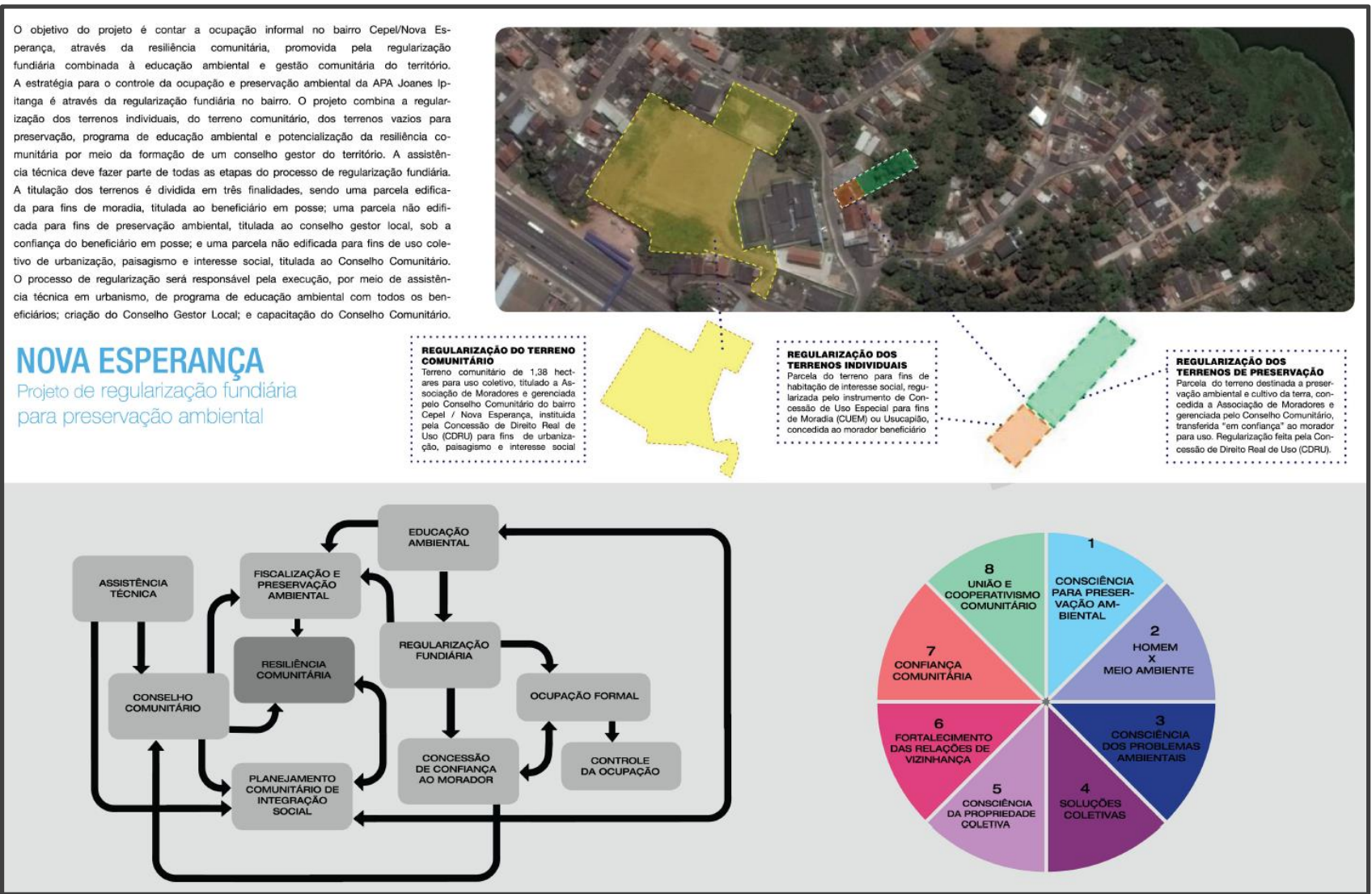

Fonte: Elaboração do autor, com base em aerofotos, 2006-PMS (BORGES, 2015).

É também referência nesta proposta a experiência do Community Land Trust (Confiança de terra à comunidade), uma forma de propriedade que envolve a aquisição da terra e edificação de residências a baixo custo, promovidas por comunidades organizadas, em que a propriedade da terra e gestão do uso do solo competem a um conselho comunitário (FIKA, 2014). A instituição desse instrumento requer dois elementos fundamentais: comunidade organizada e confiança; estes são os pilares potencializadores da resiliência comunitária, entendida como a capacidade de suportar choques e tensões sem perturbações significativas, mas renovando-se nas diversas dimensões que envolvem a autogestão nos processos de ocupação urbana e a preservação sustentável de águas (ROCHA, 2013).

\section{A INOVAÇÃO DA PROPOSTA}

Regularização fundiária, por si só, não deve ser entendida como um instrumento de melhoria da qualidade de vida da população, pois a simples titulação pode significar a disponibilização de mais terras no mercado, ou apenas a segurança jurídica da moradia. Sabemos que a simples titulação fundiária em uma determinada localidade pode gerar o fenômeno de gentrificação, que significa a expulsão das populações mais pobres pela simples lógica de mercado; enquanto que a garantia da segurança jurídica de moradia pode vir sem a própria titulação, através de instrumentos de zoneamento especial.

Assim sendo, levantou-se o questionamento, no caso deste trabalho: Qual o elemento de inovação na regularização fundiária que contribuiria para a preservação ambiental? Que proposta evitaria o parcelamento informal de terras, com aceitação da comunidade?

O elemento diferencial desta proposta está na composição da titulação em regularização fundiária de uso misto e restritivo, com a perspectiva de promover o fortalecimento da gestão comunitária sobre a propriedade coletiva e sobre o controle da ocupação e preservação ambiental. No que se refere ao lote residencial, este seria titulado em duas parcelas com finalidades diferentes: 1) uso de moradia, onde existe a edificação, 
propondo-se implementar um instrumento de regularização com fins de moradia; 2) com finalidade agroecológica, onde não existe edificação e sim isso uso agrícola, sendo o objetivo principal o de preservar o meio ambiente e promover o desenvolvimento sustentável. Nesse caso, propõe-se implantar um instrumento de usufruto, que inviabilize novas edificações e parcelamentos, incentivando arborização.

Dessa forma, combinando propriedade e posse, cada morador teria o direito de utilizar parte do terreno para proteção ecológica, desde que preservando a vegetação. Por outro lado, seria possível regularizar parte do terreno para habitação, onde já existe edificação. Observa-se que o título de propriedade da edificação é vinculado a parcela de posse agroecológica. Espera-se que, dessa forma, os beneficiários venham a assumir a posição de "guardiões" das áreas de preservação ambiental, cultivando árvores frutíferas e flora nativa.

O fortalecimento do compromisso de preservação pelos moradores encontra respaldo também na perspectiva da regularização fundiária do terreno de uso comunitário. A regularização deste terreno leva ao segundo elemento de inovação desta proposta, a regularização de propriedade coletiva. Utilizando-se também de instrumento de usufruto, a autorização de uso do terreno comunitário deve ser titulada à comunidade, pois o terreno vem sendo preservado historicamente pela posse coletiva. Nesse caso, a alternativa apresentada é que seja criado um Conselho Gestor do Território, formado pela população do bairro no processo de regularização da terra.

O objetivo do Conselho é definir os usos do terreno comunitário, negociando com a gestão pública a implantação de equipamentos urbanos e paisagismo; controlar o uso do solo no bairro, evitando descumprimento de parâmetros urbanísticos pactuados; e fiscalizar a preservação ambiental e uso das parcelas agroecológicas, tituladas por Concessão de Direito Real de Uso (CDRU). Este Conselho será o responsável por garantir a manutenção da faixa de preservação ambiental instituída pelo Conselho Gestor da APA e a conservação da biodiversidade local.

A criação do Conselho Gestor do Território tem o objetivo de gerenciar o uso do terreno comunitário, além de controlar a preservação das faixas de proteção ambiental, tanto aquelas que estão às margens do manancial, quanto as parcelas correspondentes aos quintais das casas, com finalidade agroecológica. Este Conselho deve assumir o papel de mediador entre a gestão municipal e os anseios da comunidade, e estar relacionado ao Conselho Gestor da APA Joanes Ipitanga, funcionando como integrante da estrutura de fiscalização e controle da preservação ambiental no local.

Dentro do projeto de regularização, a formação deste Conselho constitui uma estratégia de fomentar a participação da comunidade no processo de regularização fundiária. $O$ processo de constituição de um estatuto e composição dos membros deve mobilizar toda a população a ter seus anseios representados no Conselho, visto que cada beneficiário deverá assumir o papel de fiscal do meio ambiente, inclusive fiscalizando seus vizinhos.

Além do papel de fiscalização e controle do uso do solo e da preservação, o Conselho será o responsável pela discussão do planejamento do bairro, indicando diretrizes de desenvolvimento, implantação de equipamentos urbanos e programas e projetos de urbanização local e desenvolvimento socioeconômico, além da gestão do terreno de posse comunitária.

\section{REFERÊNCIAS}

BAHIA, Governo do Estado. Decreto Estadual 32.91506 de fevereiro. Institui o Parque Metropolitano Ipitanga. Salvador, 1986.

BAHIA, Governo do Estado. Decreto Estadual 7.596 de 05 de junho. Cria a Área de Proteção Ambiental - APA de JoanesIpitanga e dá outras providências. Salvador, 1999

BORGES, I. A, Regularização fundiária para preservação ambiental - Nova Esperança/lpitanga, apresentado em janeiro de 2015. Disponível em: < http://www.residencia-aue.ufba.br/igor-alves-borges>. Acesso em: dezembro de 2015.

FIKA, O. Land Management Course and Informal Settlement Regularization (LMISR11), Community Land Trust, at Institute for Housing and Urban Development IHS. Rotterdam, julho de 2014.

GORDILHO-SOUZA, A. M. A lei de responsabilidade territorial urbana e a construção da cidade democrática. Anais do Encontro ANPUR, 58aㅜ reunião anual da SBPC. Florianópolis, julho de 2006. 
GORDILHO-SOUZA, A. M. Regularização fundiária na nova política municipal de habitação de interesse social de Salvador. Salvador: Revista Veracidade, junho de 2007.

IBGE. Censo demográfico 2010. Rio de Janeiro, 2011. Disponível em: <http://www.ibge.gov.br/home/estatistica/populacao/censo2010/default.shtm>. Acesso em: março de 2014.

ROCHA, H. F. (2013). Cidades em transição e outros ideários urbanos: novas utopias urbanísticas? In: SEMINÁRIO URBANISMO NA BAHIA - URBA13. Salvador: Anais. Disponível em: <http://urbba13.blogspot.com.br/p/trabalhoscompletos.html>. Acesso em: março de 2014>.

SARNO, C. M. Manancial do Ipitanga, última fronteira na expansão urbana de Salvador: o urbano e o ambiental na perspectiva do direito à moradia. Dissertação de mestrado. Programa de Pos-Graduação em Arquitetura e Urbanismo. Salvador, 2011

\section{NOTAS}

${ }^{1}$ O diagnóstico participativo e o caderno de propostas deste trabalho de assistência técnica foram elaborados em grupo durante a Residência em Arquitetura e Urbanismo da Universidade Federal da Bahia, no período de fevereiro a outubro de 2014. O grupo de trabalho foi integrado por Ana Claudia Teixeira Frederico Balani, Cleiton Airon Alves Arruda, Igor Alves Borges, Rafaela Costa Alonso e Vagner Damasceno Freitas de Cerqueira. O grupo foi coordenado pelas professoras orientadoras Dra. Angela Maria Gordilho Souza e Me. Heliana Faria Mettig Rocha, sendo a primeira, tutora deste projeto.

NOTA DO EDITOR (*) O conteúdo do artigo e as imagens nele publicadas são de responsabilidade do(s) autor(es). 